\title{
Е.М. РУДАКОВА
}

инженер управления капитального строительства ОАО «Куйбышевский НПЗ», аспирант кафедры строительных материалов

\section{A.Е. ФРО}

ведущий инженер ОНИИ «Реконструкция»

Самарский государственный архитектурно-строительный университет

\section{ПОВЫШЕНИЕ БЕЗОПАСНОСТИ ЖЕЯЕЗОБЕТОННЫХ КОНСТРУКЦИЙ В УСЛОВИЯХ АГРЕССИВНЫХ СРЕД}

\author{
IMPROVING THE SAFETY OF REINFORCED CONCRETE STRUCTURES IN THE CONDITIONS \\ OF CORROSIVE ENVIRONMENTS
}

Здания и сооружения, расположенные на территориях предприятий химического и нефтехимического профиля, требуют проведения работ по поддержанию основных несущих әлементов в работоспособном состоянии. При проведении экспертизы промышленной безопасности составляется заключение о степени технического состояния отдельных әлементов и конструкций сооружений в целом. Также устанавливаются основные факторы, вызывающце разрушение основного строительного материала и отказ работы конструкичии.

Ключевые слова: бетон, безопасность, промышленная безопасность, коррозия, агрессивная среда.

Основные предприятия нефтехимического производства относятся к объектам повышенной промбезопасности. 70 \% повреждений строительных объектов приходится на химическую коррозию материала конструкций.

Коррозия представляет собой непрерывный процесс, обусловливающий скорость коррозии, зависящий от агрессивности среды и вида конструкционного материала.

Изменение физико-технических свойств материалов и их деструкция из-за коррозии иногда приводят строение к аварийному состоянию.

Интенсивное промышленное строительство 6070-х гг. прошлого столетия осуществлялось на базе типовых проектов, представленных в «Общесоюзном каталоге индустриальных изделий для промышленного и гражданского строительства» Госстроя СССР.

Несущие железобетонные конструкции , применяемые в строительстве зданий и сооружений в бывшем СССР, удовлетворяют в основном требованиям норм к конструкциям, используемым в слабои среднеагрессивных средах.
Buildings and constructions located on the territory of the enterprises of chemical and petrochemical profile require works on the maintenance of the basic bearing elements in working condition. When carrying out expert examination of industrial safety is drawn a conclusion on the degree of technical state of individual elements of constructions and buildings in General. Also identifies the main factors causing the destruction of the main building material and the refusal of the work of construction.

Keywords: concrete, safety, industrial safety, corrosion, aggressive environment.

В сильно агрессивных средах требуется специальная антикоррозионная защита, а стальные несущие конструкции в условиях сред любой степени агрессивности без специальной антикоррозионной защиты к эксплуатации не допускаются. В существующих указаниях по защите конструкций от коррозии имеются многочисленные несоответствия с действующими в настоящее время нормами.

Анализ многочисленных обследований показал, что типовые железобетонные конструкции, эксплуатируемые на предприятиях нефтехимической промышленности в агрессивных средах, имеют значительные разрушения, а на отдельных объектах находятся в аварийном состоянии. На рис. 1 и 2 можно увидеть следы коррозионного воздействия растворов, которые попадают на перекрытия, когда на них размещается оборудование. Чаще всего такие картины можно наблюдать в зданиях-постаментах, когда над насосными располагаются обордувание и технологические этажерки.

По рис. 2 можно предположить наличие значительной коррозии, имеющейся в балке, поскольку 


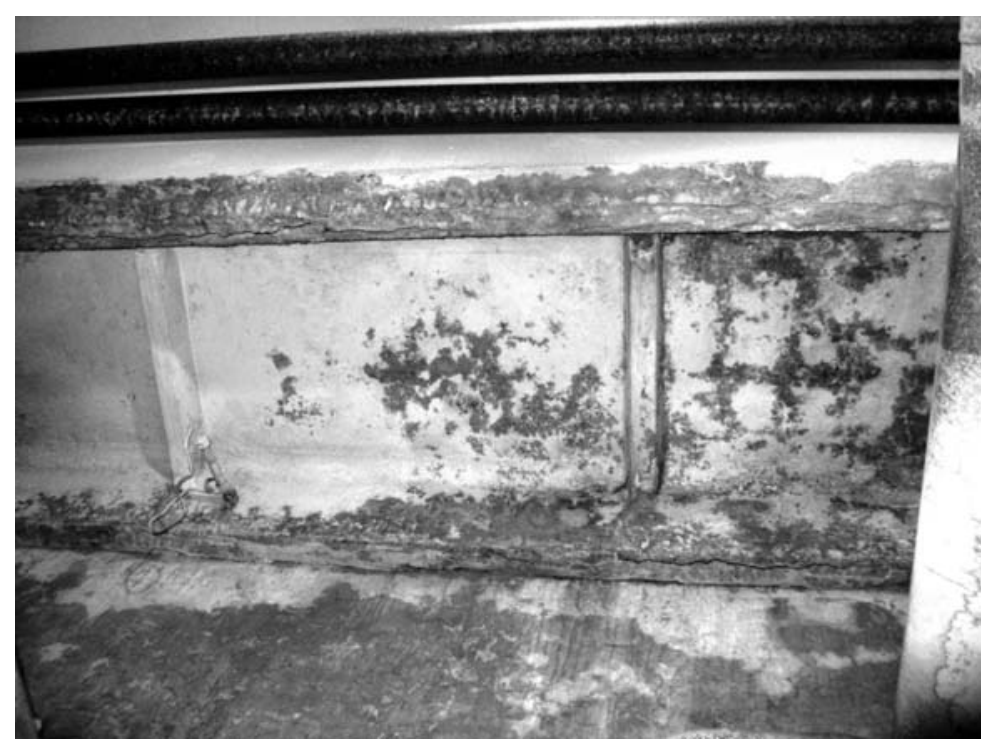

Рис. 1. Начальное нарушение защитного слоя плиты, на которой проступают следы растворов

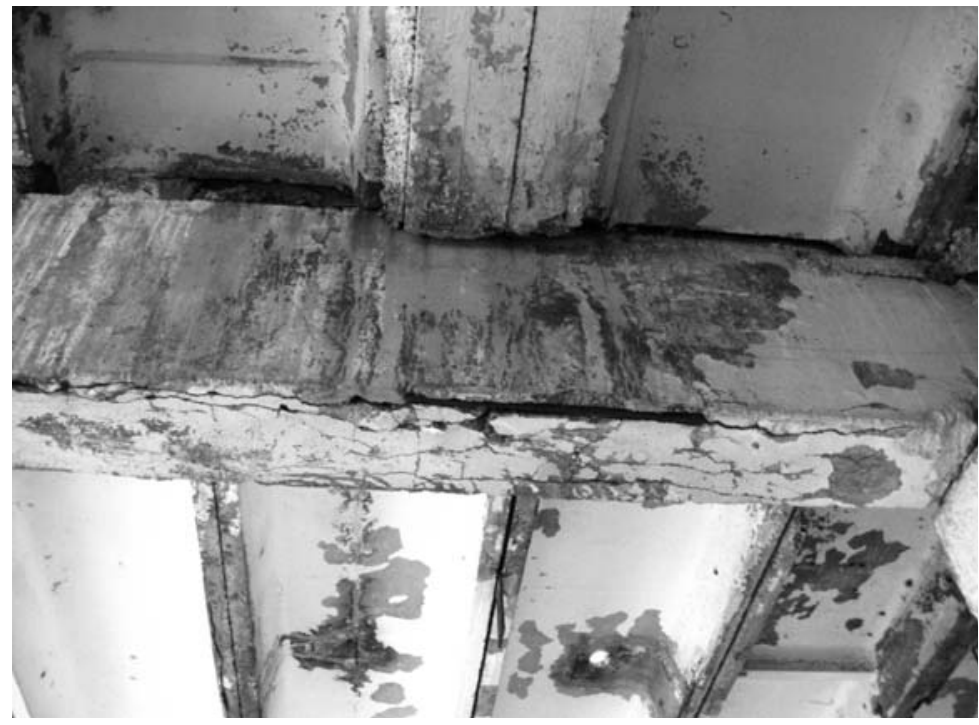

Рис. 2. Вторичное разрушение железобетонных перекрытий

раскрытые продольные трещины свидетельствуют о большом увеличении слоя коррозии арматуры, который разрывает и отторгает защитный слой бетона.

Особое внимание следует обращать на преднапряженные железобетонные конструкции, армированные термически упрочненной высокопрочной арматурой, эксплуатация которых, с учетом коррозии, может привести к развитию поперечных трещин и мгновенному разрушению.

Коррозия (от латинского разъедать) - самопроизвольное разрушение твердых тел, вызванное химическими и электро-химическими процессами, развивающимися на поверхности тел при взаимодействии с внешней средой.
Коррозия бетона - необратимое ухудшение его свойств и характеристик в результате химического, физико-химического или биологического воздействия коррозионной среды или внутренних процессов в бетоне.

Коррозия железобетона - ухудшение его технических характеристик в результате коррозии бетона и/или арматуры [1].

Коррозия, отрицательно сказываясь на состоянии конструкций, является причиной снижения их надежности - способности выполнять требуемые функции в течение расчетного срока эксплуатации [2].

В зданиях и сооружениях предприятий нефтехимии широко используются бетонные и железобетон- 
ные конструкции, которые подвергаются воздействию окружающей среды в виде несилового воздействия на бетон в конструкции иди сооружении, вызванного физическими, химическими, биологическими или иными проявлениями, приводящими к изменению структуры бетона или состояния арматуры.

Химические и нефтехимические производства явдяются источником повышения агрессивности окружающей среды.

Агрессивная среда - это среда эксплуатации объекта, вызывающая уменьшение сечения и деградацию свойств материала во времени.

По физическому состоянию агрессивные среды разделяются на газообразные, жидкие и твердые.

Степень воздействия газообразных сред зависит от группы газов и температурно-влажностного режима зоны влажности территории.

Влияние жидких сред определяется наличием и концентрацией агрессивных агентов, скоростью движения их у поверхности конструкции; твердые среды (соли, аэрозоли, пыль, грунты) оцениваются дисперсностью, растворимой в воде, влажностью, гигроскопичностью.

Нормативные документы раздичают четыре степени агрессивности, определяющие вид среды: неагрессивные, слабо агрессивные, средне агрессивные и сильно агрессивные. При анализе вдияния на метали степень агрессивности определяется величиной потери единицы тодщины сечения в единицу времени (милдиметр в год).
Дия учета влияния агрессивности среды на бетон и железобетон ГОСТ 31384-2008 [3] предлагает оценивать ее степень глубиной разрушения защитного слоя или потери защитного действия по отношению к стальной арматуре, произошедших за 50 лет эксплуатации:

- не более 10 мм - при слабой степени;

- не более 20 мм - при средней степени;

- 20 мм и более - при сильной степени агрессивности.

Повреждение бетона в зоне контакта с окружающей средой провоцируется порами в теле и трещинами на поверхности. За счет диффузионного процесса агрессивная среда проникает внутрь; и чем больше пористость, тем глубже распространяется воздействие, снижающее прочность материала.

На рис. 3 представлен вид полностью разрушенного защитного слоя, где крупный заполнитель освобожден от связи вяжущего. На рис. 4 и 5 четко видна деструкция бетона в виде расслоения защитного слоя и вымывания цементного связующего.

Дия предотвращения коррозионного разрушения предусматриваются защиты: первичная, вторичная и спецьиальная.

K первичной защите относятся мероприятия, позводяющие повысить пдотность и стойкость бетона с помощью специальных добавок и цементов, а также подбором состава бетона, снижающего проницаемость. Кроме того, используются конструктивные приемы.

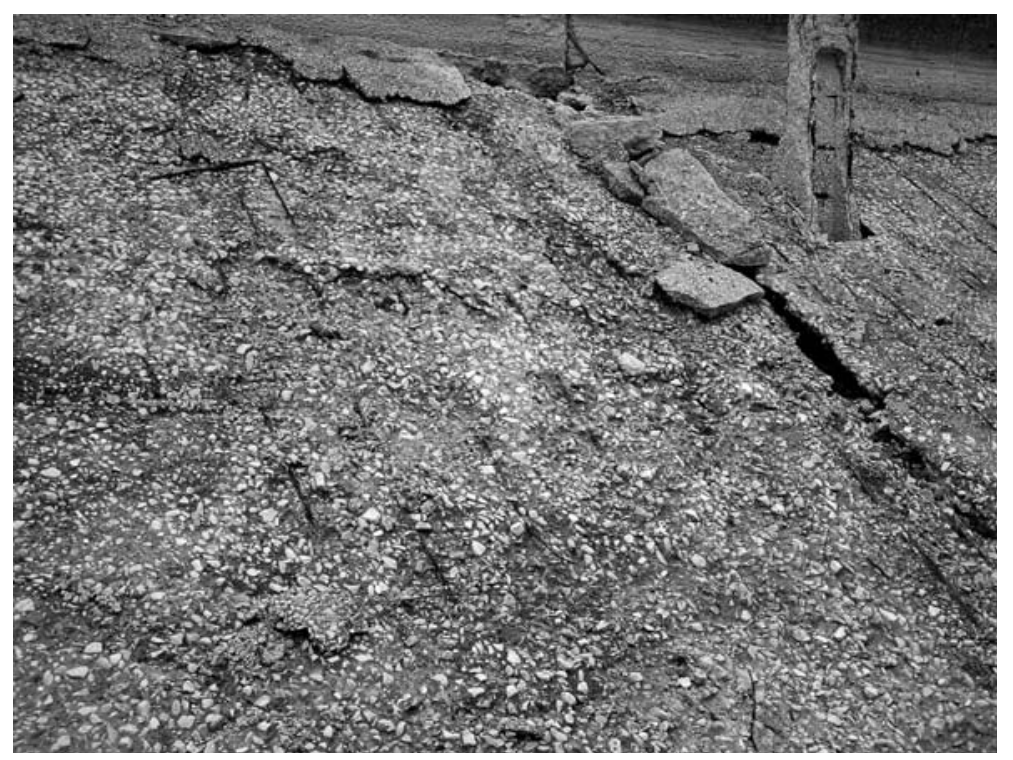

Рис. 3. Поверхность железобетонного днища отстойника, изъеденная закисленными стоками, с интенсивным разрушением тела бетона

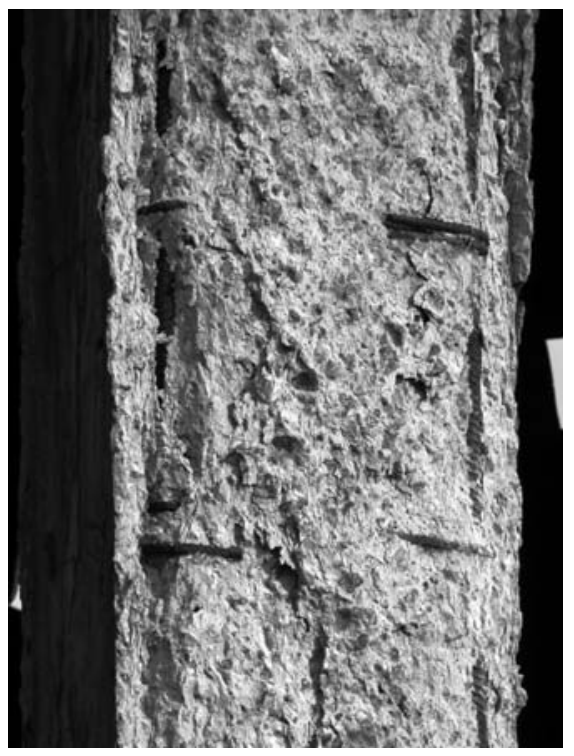

Рис. 4. Характерное пористое разрушение тела бетона от коррозии 


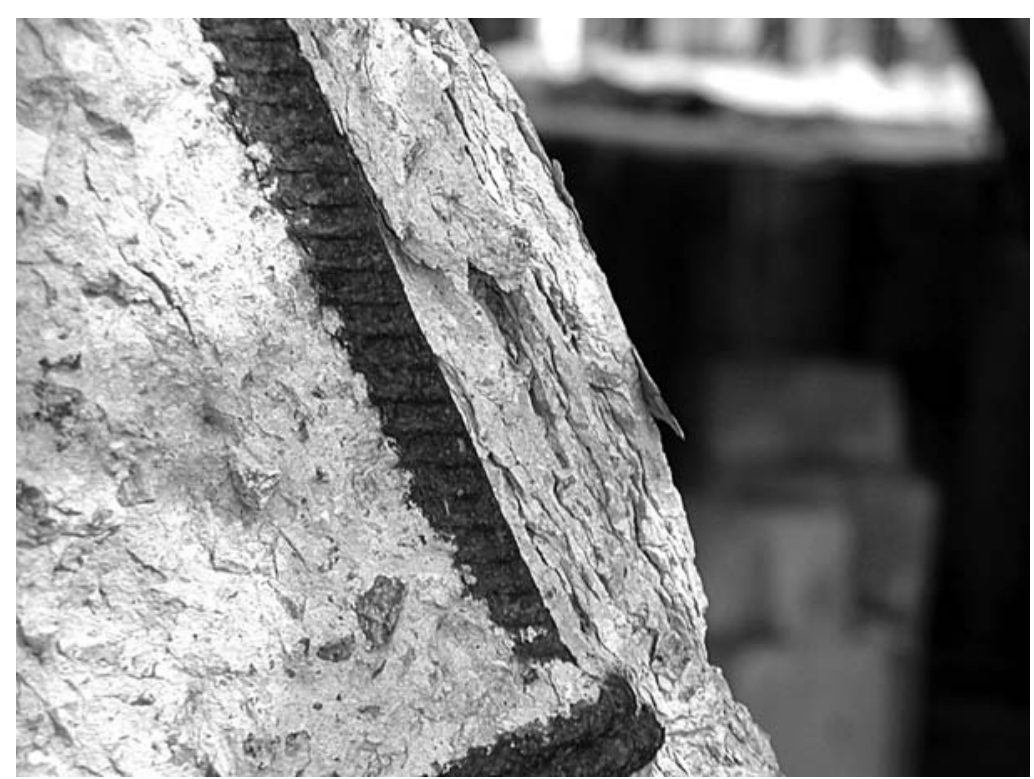

Рис. 5. Расслоение защитного слоя бетона и начинающая коррозия арматуры

К мерам вторичной защциты относятся обработка поверхностей конструкций покраской, обмазкой или пропиткой, которые препятствуют проникновению агрессивных агентов внутрь. Вторичная защита требует периодического обновления. Однако она необходима при недостаточности первичной защиты.

Кроме того, вторичная защита бывает необходимой для открытых сооружений, подвергаемых, помимо агрессивных, более интенсивным температурно-влажностным воздействиям.

Когда речь заходит о защите конструкций в условиях агрессивной химической среды, то материалы вторичной защиты должны обладать стойкостью к ней.

Так как бетон имеет хорошую гигроскопичность, то для него преимущественно применяют жидкие упрочняющие составы, но существуют и сухие строительные смеси, которые используют при втирании их в поверхностные слои железобетонных конструкций [4].

Ими могут явдяться раздичные подимерные композиты, достаточно стойкие к действию растворов кислот. Также применяются жидкости, которые, проникая в поры бетона, через определенное время полимеризуются.

Существует несколько видов защитных покрытий. Одними из них являются материалы, которые при нанесении образуют защитное покрытие, раздичное по толщине, начиная от пленочного и заканчивая нанесением торкрет-бетонного покрытия. Выбор того или иного способа и материала будет зависеть от вида разрушения бетона, условий эксплуатации, технологического процесса выполнения работ.

Большинство предприятий работают без остановки производственного процесса, так как это связано с затратами на остановку, чистку и временную консервацию. По этой причине большинство ремонтных работ производят в действующих зданиях и сооружениях. По этой причине важно исподьзовать материалы, способные быстро набирать проектную прочность и обеспечивать совместную работу с уже существующими конструкциями.

Дия повышения безопасности при эксплуатации железобетонных конструкций в условиях агрессивного воздействия сред пористость следует уменьшить.

Чтобы повысить плотность материала без его существенного утяжеления, применяют пропитки. Их номенклатура обширна. В большинстве своем - это материалы на основе полимеров или одигомеров.

Полимеры (от греч. polymeres - состоящий из многих частей, многообразный) - это химические соединения с высокой молекулярной массой (от нескодьких тысяч до многих мидлионов), молекуды которых (макромолекулы) состоят из большого числа повторяющихся группировок (мономерных звеньев). Атомы, входящие в состав макромолекул, соединены друг с другом силами главных и (или) координационных валентностей.

Олигомеры - члены гомологических рядов, занимающие по размеру молекул область между мономерами и высокомолекулярными соединениями. Верхний предел их молярных масс зависит от хими- 
ческой природы и соответствует тому значению, при котором начинают проявляться высокоэластические деформации, вынужденная высокоэластичность и другие свойства, характерные для высокомолекулярных веществ.

При нанесении на поверхность железобетонной конструкции материалы, содержащие в своем составе полимеры или олигомеры, закупоривают верхние открытые поры, создавая защитный слой. В зависимости от своего состава и температуры нанесения, процесс его затвердевания будет происходить с разной скоростью. От этого также будет зависеть величина защитного слоя. Поверхностная обработка возможна только при условии, если тело конструкции не разрушидось или тодько вводится в эксплуатацию.

Когда состояние неудовлетворительное, есть следы разрушения материала или же железобетон пострадал от действия на него растворов кислот или же атмосферных осадков, то в этом случае происходит восстановдение конструкции до проектных размеров. Для этого применяют торкретбетон или же бетоны со специальными добавками. Примером этого может служить полимерботон, который в своем составе содержит большое кодичество подимера, что повышает адезионные свойства нового материала к старому и увеличивает кислотостойкость конструкции [5].

Еще одним вариантом может быть обработка материалов специальными жидкими составами, например, стиролом. Этот материал широко используется для упрочнения бетона, создания антикоррозионных и гидроизодирующих покрытий бетонных и металдических конструкций.

Также для упрочнения поверхностного слоя бетона и создания нового материала бетонополимера применяют мономеры (от греч. monos - один и meros - часть), низкомолекулярные соединения, молекулы которых способны реагировать между собой или с молекулами других соединений с образованием полимеров. Мономерами служат соединения, содержащие в себе кратные связи (например, олефины, диены, ацетилены, производные ненасыщенных карбоновых кислот).

Проникая в микропоры по сети капилляров, мономеры или составы с ними заполняют все свободное пространство. Через определенное время происходит процесс подимеризации и уплотнение поверхностного слоя, что повышает водо- и химическую стойкость материала. Когда процесс корро- зионного разрушения замедляется, то жизненный цикл сооружений увеличивается [6]. Благодаря этому надежность эксплуатации строительных конструкций из железобетона увеличивается.

Во всех конкретных случаях и на каждом предприятии количество применяемого мономера, а также способы его нанесения будут отличаться. Для точного определения его количества необходима консультация специалистов в области промышленной безопасности, которые определят среду эксплуатации конструкций и дадут рекомендации по повышению долговечности строительных конструкций зданий и сооружений.

\section{БИБАИОГРАФИЧЕСКИЙ СПИСОК}

1. ГОСТ Р 52804-2007. Национальный стандарт Российской Федерации. Защита бетонных и железобетонных конструкций от коррозии. Методы испытаний. Издание официальное [Текст]. - М.: Стандартинформ, 2008.

2. ГОСТ Р 54257-2010. Национальный стандарт Российской Федерации. Надежность строительных конструкций и оснований. Основные положения и требования. Издание официальное [Текст]. - М.: Стандартинформ, 2011.

3. ГОСТ 31384-2008. Межгосударственный стандарт. Защита бетонных и железобетонных конструкций от коррозии. Общие технические требования. Издание официальное [Текст]. - М.: Стандартинформ, 2010.

4. Баженов, Ю.М. Бетонополимеры [Текст] / Ю.М. Баженов. - М.: Стройиздат, 1983.

5. Соломатов, В.И. Химическое сопротивление материалов. 2-е изд., перераб. и дополн [Текст] / В.И. Соломатов, В.П. Селяев, Ю.А. Соколова. - М.: PAACH, 2001. -284 c.

6. Коренькова, С.Ф. Принципы предварительной соподимеризации двух мономеров. Итоги диссертационных исследований [Текст] / С.Ф. Коренькова, С.Я. Карасева, Е.М. Рудакова // Материалы IV Всероссийского конкурса мододых ученых. Том 3. - М.: РАН, 2012. - 118 с.

() Рудакова Е.М., Фролов А.Е., 2013 